\title{
Supporting Kenyan women with advanced breast cancer through a network and assessing their needs and quality of life
}

\author{
Asim Jamal Shaikh ${ }^{1}$ (1) Niha Dhillion ${ }^{2} \cdot$ Jasmit Shah $^{3} \cdot$ Caroline Kathomi $^{4} \cdot$ Alfred Kiragu $^{5} \cdot$ Fredrick Chite Asirwa $^{6}$. \\ Catherine Nyongesa $^{7} \cdot$ Riaz Kasmani $^{8} \cdot$ Innocent Abayo $^{1} \cdot$ Grace Kirathe $^{1} \cdot$ Shahin Sayed $^{9}$
}

Received: 30 November 2020 / Accepted: 4 September 2021 / Published online: 19 September 2021

(c) The Author(s), under exclusive licence to Springer-Verlag GmbH Germany, part of Springer Nature 2021

\begin{abstract}
Introduction Metastatic breast cancer (MBC) patients have several unmet needs. The needs and quality of life of MBC women living in sub-Saharan Africa (SSA) are understudied. Facilitating the interaction of various caregivers is beneficial in addressing the needs. Internet-based resources play an important role in reaching out to these patients. We aimed to bring the various stakeholders into a joint network force, create a web-based portal, understand the needs of MBC patients, and assess the utilization of web-based resources for women from Kenya.

Methods A network of various stakeholders considered crucial in the care of Kenyan women with MBC was created. We conducted educational camps and assessed their needs, quality of life (QoL), and knowledge. We assessed the impact of utilizing web-based resources by MBC patients from here.

Results We formed a network involving partners and launched the first dedicated website for MBC from Kenya. The website has received 13,944 visits and 310,379 hits in 2 years. One hundred fourteen women living with MBC were interviewed, and our findings show that psychological needs (63\%), physical support needs $(60 \%)$, and health care system needs $(55 \%)$ are leading areas of needs that increase with rural residence $(p=0.001)$, less education $(p=0.003)$, and aggressive treatments $(p=0.008)$. Quality of life (QoL) confirmed better scores with urban residence $(p=0.002)$, internet access $(p=0.010)$, and stable disease $(p=0.042)$.

Conclusions Creating a network of caregivers provides opportunities for cohesive efforts in understanding the psychosocial and medical needs of patients with MBC. Internet-based resources are an effective way of reaching out to them. Kenyan patients show extremely good uptake of internet-based resources.
\end{abstract}

Keywords Breast cancer support $\cdot$ Metastatic $\cdot$ Kenya $\cdot$ Web support $\cdot$ Breast advocacy

\section{Introduction}

Breast cancer $(\mathrm{BC})$ is the most common cancer in Kenya with approximately 6,000 new cases per year [1]. The majority of BCs in Kenya present at an advanced stage [2, 3]. In

Asim Jamal Shaikh

asim.jamal@aku.edu

1 Department of Hematology and Oncology, The Aga Khan University Hospital, Nairobi 00100, Kenya

2 School of Public Health, University of Washington, Seattle, WA, USA

3 Department of Internal Medicine, The Aga Khan University Hospital, Nairobi, Kenya

4 Department of Population Health, The Aga Khan University Hospital, Nairobi, Kenya addition, $30 \%$ of women diagnosed with early breast cancer eventually develop metastatic disease [4]. Metastatic breast cancer (MBC) therefore comprises a significant population of women living with breast cancer. Patients living with $\mathrm{MBC}$ are recognized to be a special group with unique

5 National Cancer Institute of Kenya, Ministry of Health, Nairobi, Kenya

6 Office of Cancer Prevention, Surveillance, and Precision Medicine, International Cancer Institute, Eldoret, Kenya

7 Texas Cancer Centre, Nairobi, Kenya

8 The Aga Khan Hospital, Mombasa, , Mombasa, Kenya

9 Department of Pathology and Laboratory Medicine, The Aga Khan University Hospital, Nairobi, Kenya 
unmet needs [5]. The specific needs and quality of life (QoL) issues, for patients with MBC in sub-Saharan Africa (SSA), have especially been neglected. There has been very little effort on utilizing internet-based platforms for helping women with MBC from here, whereas there is known to be an effective modality [6]. Internet penetration of up to $43 \%$ among the Kenyan population provides a good opportunity to explore the utilization of this strategy [7]. To identify and address the gaps in needs and QoL of MBC patients, we aimed to develop a nationwide network of physicians, health care advocates, governmental and non-governmental organizations, faith-based groups, psychologists, nursing advocates, support groups, and social organizations to come together to identify the needs and improve QoL of MBC patients in Kenya. Supported by the Union for International Cancer Control (UICC), we conducted seminars and sessions for patients with $\mathrm{MBC}$ in multiple cities within the Republic of Kenya, in an attempt to educate them, engage them, learn from them, and have open discussions about their needs, QoL, and knowledge of breast cancer. We launched an interactive website dedicated to women with MBC in Kenya, called the Kenya Metastatic Breast Cancer Network (www. kmbcn.org). The first of its kind support tool for women with $\mathrm{MBC}$ from here. We present our experience of developing a web-based platform and findings from our interactions with Kenyan women living with MBC and the results of the needs assessment, QoL, and level of knowledge surveys from these interactions. We also present the uptake and utilization of internet-based resources in this population.

\section{Methods}

\section{Setting up Kenya Metastatic Breast Cancer Network}

Led by the principal investigator (PI) at the Aga Khan University Hospital, Nairobi (AKUHN), we initiated contacts with all stakeholders involved in the care of breast cancer patients including private and government partners. The stakeholders as described above established the Kenya Metastatic Breast Cancer Network (KMBCN). Supported by a grant from the Union of International Cancer Control (UICC) [8], the major goal of KMBCN was to recognize this marginalized community of breast cancer, reach out to them physically and virtually, identify their needs, and attempt to improve their QoL in urban and rural Kenya.

It was recognized that efforts would need to be made to reach out to these women proactively. The stakeholder group met several times at AKUHN to brainstorm an approach to reach out to these women. It was recognized that physical and virtual platforms would be used to identify their needs, assess their QoL, assess their knowledge about their disease, and hold educational sessions to provide first-hand information that they need.

\section{Developing a website}

Developing a virtual online interactive support forum was central to this endeavor [8], through which MBC patients and their caregivers could access information on social, psychological, spiritual, religious, and clinical needs. The online platform further allowed these women opportunities to interact with various support providers, remain abreast with support and educational activities, and know about the latest updates in the country on MBC. An online website called http://www.kmbcn.org, representing the KMBCN, was launched in August 2018 in Nairobi. The website content was intended to be culturally sensitive and customized for Kenyan women with MBC and their caregivers. A core team responsible for overseeing the professional and technical content for the website was formed and led by the PI, grant recipient of the UICC SPARC project. The website is fully interactive and has the capability for calendar integration to link events. Links to local, regional medical facilities with map directions, and for spiritual, psychological, religious, and other support groups were provided. Links to useful internet resources such as guidelines for patients and global support groups were provided as well. The website content also included the latest news, upcoming events, and trending topics, announcements, publications insights, reflections, and patient stories. The registration and information aspect of the website allows users to create their profiles, interact with caregivers about their concerns, and ask questions. Caregivers from various cadres were identified as champions of updating the information on the website and responding to questions posed by users. Endorsements were sought from major stakeholders including the National Cancer Institute of Kenya, Ministry of Health, and Kenya Society of Hematology and Oncology (KESHO). Pamphlets on basic MBC awareness with links to the website were distributed to major hospitals and various points of health care delivery including county, district, and local hospitals. Social media links were created and linked to the website. Following the launch, the PI and other team members visited all the participating sites to create awareness of the website among health workers and provide hands-on training on functionalities and navigation of the website. Technical management teams monitored the website to maintain security, the legality of the content, the authenticity of the users, privacy, prevention of piracy, and spam content.

The website is continuously updated and modified to remain current and reflect local concerns. The overall activity of the website is supervised, moderated, and monitored by the PI with the assistance of the core group assigned this task. 


\section{Understanding the needs, QoL, and knowledge}

From July 2018 to July 2019, we held five educational camps for women with MBC. Supported by our partners in this endeavor, we held sessions in the cities of Mombasa, Eldoret, and Nairobi. During the awareness sessions, team members from KMBCN made presentations on various aspects of breast cancer, from the role of screening to treatment with a focus on the need of understanding the value of integrated care. During these meetings, one-to-one interviews and surveys were conducted on women with single inclusion criteria of living with metastatic breast cancer and having a European Cooperative Oncology Group (ECOG) performance status of $0-2$, to assess their needs, QoL, and knowledge. After seeking appropriate approvals, for needs assessment, we used the Supportive Care Needs Survey short format (SCNS-SF34) [9], for QoL we used the Functional Assessment of Cancer Therapy-Breast Cancer (FACT-B) validated instrument [10], and we used an internally developed previously validated BC Knowledge assessment tool from the Aga Khan University (AKU) [11] to assess the knowledge of breast cancer. The surveys were administered on paper, and the data was then entered electronically.

\section{Statistical methods}

For analyzing the quantitative data on the assessment of needs, QoL, and knowledge of BC, categorical data were presented as frequencies and percentages, whereas continuous data were presented as median and interquartile ranges. Univariate analysis was conducted using Fisher's exact test for categorical data and a non-parametric test (Mann-Whitney test) for continuous data. Pairwise comparisons where there were more than 2 groups were also conducted. Spearman's correlations were used to identify the bivariate correlations among the needs and FACTB surveys. A $p$-value of $<0.05$ was considered statistically significant.

\section{Website data}

The data on the assessment of website utilization was collected through AWStats. AWStats is an open-source Web analytics-reporting tool, suitable for analyzing data from internet services such as web, streaming media, mail, and FTP servers.

\section{Ethical approvals}

The study was conducted in compliance with ethical principles adapted through and under the declaration of accordance of Helsinki. Complete confidentiality was observed, and interviews were conducted following written informed consent. Formal ethical approvals were obtained from the
Institutional Ethics Review Committee (IERC) at AKUHN and National Commission for Science, Technology, and Innovation (NACOSTI), Ministry of Education, Kenya.

\section{Results \\ KMBCN activities}

The study team members who participated and formed the core group met every 2 months and provided input on the content of the website. A professional website developer worked closely with the core group, activities were relayed to social media, and content development was jointly planned to keep in mind cultural sensitivities and a volunteer intern worked closely with the PI to collate all the content.

\section{Assessment of needs, QoL, and knowledge}

This study enrolled 114 patients. The mean age of the patients was 51.4 years $(\mathrm{SD}=12.7)$, and $56.1 \%$ of the patients were married. The majority of the patients (92.9\%) were of African ethnicity, and $90.2 \%$ were following Christianity. More than half (54.6\%) resided in rural areas whereas only $23.7 \%$ had tertiary education.

\section{Needs assessment}

Analysis of 114 patients, as shown in Table 1, showed that $103(90.4 \%)$ patients reported at least one "moderate to high" level unmet supportive care need and only 5 (4.4\%) reported no needs. The top 10 items that patients reported a moderate to a high level of need for help with are also shown in Table 1. The most unmet needs concerning psychological issues (63\%), needs around daily living and physical support (60.5\%), and needs around health care systems (55.4\%) are shown in Fig. 1. Univariate analysis on the needs assessment showed that psychological needs were highest among patients living in rural areas $(p=0.001)$, who were less educated $(p=0.003)$, with worsening disease $(p=0.001)$, and those who were on systemic chemotherapy $(p=0.008)$. Health Information needs were higher with advanced metastatic disease $(p=0.017)$, having the worsening disease $(p=0.001)$, and those receiving systemic chemotherapy $(p=0.004)$. Needs on daily living were highest in those living in rural areas $(p=0.007)$, less educated $(p=0.009)$, having no internet access $(p=0.032)$, and those with worsening disease $(p=0.001)$. The needs on sexuality were higher in married $(p=0.001)$ and pre-menopausal women $(p=0.014)$. The needs for patient care and support were higher with worsening disease $(p=0.013)$ (Tables 2 and 3). 
Table 1 Prevalence of supportive care needs and the top ten "moderate or high" level unmet supportive care needs

\begin{tabular}{|c|c|c|c|}
\hline & & \multicolumn{2}{|l|}{ Total $(N=114)$} \\
\hline \multicolumn{2}{|c|}{ No Needs ${ }^{\mathrm{a}}$} & \multicolumn{2}{|l|}{$5(4.4 \%)$} \\
\hline \multicolumn{2}{|c|}{ Low Needs ${ }^{b}$} & \multicolumn{2}{|l|}{$6(5.3 \%)$} \\
\hline \multicolumn{2}{|c|}{ Moderate or High Needs ${ }^{c}$} & \multicolumn{2}{|l|}{$103(90.4 \%)$} \\
\hline Rank & SCNS-SF34 item & Number $(\%)$ & Domain \\
\hline 1 & Not being able to do the things you used to do & $73(64.0)$ & Physical and daily needs \\
\hline 2 & Fears about the cancer spreading & $71(62.3)$ & Psychological \\
\hline 3 & $\begin{array}{l}\text { Being given information (written, diagrams, drawings) about aspects of managing } \\
\text { your illness and side effects at home }\end{array}$ & $68(59.6)$ & Health system \\
\hline 4 & Being given written information about the important aspects of your care & $65(57.0)$ & Health system \\
\hline 5 & Work around the home & $64(56.1)$ & Physical and daily needs \\
\hline 6 & $\begin{array}{l}\text { Having access to professional counseling (e.g., psychologist, social worker, counselor, } \\
\text { nurse specialist) if you, family or friends need it }\end{array}$ & $62(54.4)$ & Health system \\
\hline 7 & Worry that the results of treatment are beyond your control & $62(54.4)$ & Psychological \\
\hline 8 & Anxiety & $61(53.5)$ & Psychological \\
\hline 9 & Being given explanations of those tests for which you would like explanations & $58(50.9)$ & Health system \\
\hline 10 & Feelings of sadness & $58(50.9)$ & Psychological \\
\hline
\end{tabular}

a Selected "no" need for help to all 34 items

belected "low" level need for help to at least one item, but did not select "moderate"

"Selected "moderate" or "high" level need for help to at least one item

Fig. 1 Proportion of the most prevalent "moderate or high" level unmet supportive care needs as per the domain

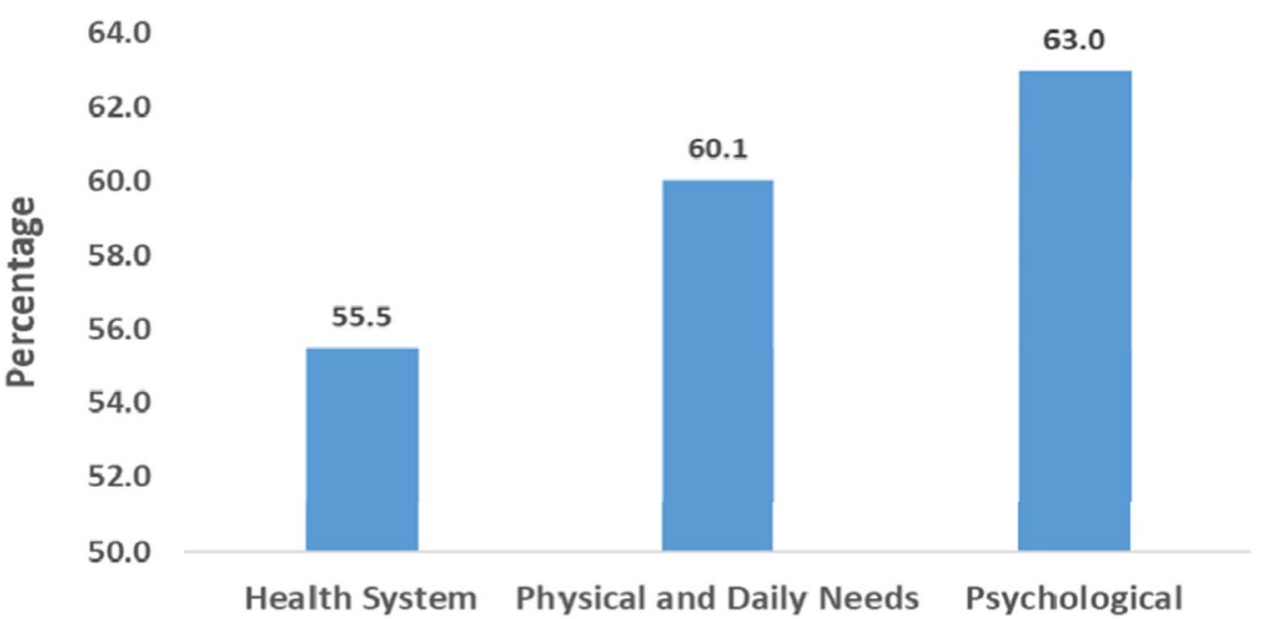

\section{QoL assessment}

Various FACT-B domains, where a higher score is better, showed that physical wellbeing (PWB) score was higher in patients living in urban areas $(p=0.002)$ and with stable disease or improving disease $(p=0.001)$. Emotional wellbeing (EWB) was higher in those that were single $(p=0.006)$, living in urban residence $(p=0.004)$, having internet access $(p=0.010)$, with stable or improving disease status $(p=0.011)$, and those on oral hormonal therapy $(p=0.001)$. Functional wellbeing $(\mathrm{FWB})$ scores were higher with urban residence $(p=0.004)$, with internet access $(p=0.010)$, with limited, single-site metastasis $(p=0.039)$, and with improving disease $(p=0.039)$. The overall FACT-G was improved for those living in an urban area $(p=0.007)$, having internet $(p=0.014)$, single site of disease $(p=0.042)$, and stable disease $(p=0.004)$. On breast cancer-specific subscale (BCS), pre-menopausal women $(p=0.009)$ and stable disease $(p=0.034)$ scored higher. FACT-B total score was better with urban residence $(p=0.003)$, having internet access $(p=0.032)$, and having stable disease $(p=0.002)$ (Table 4$)$. 


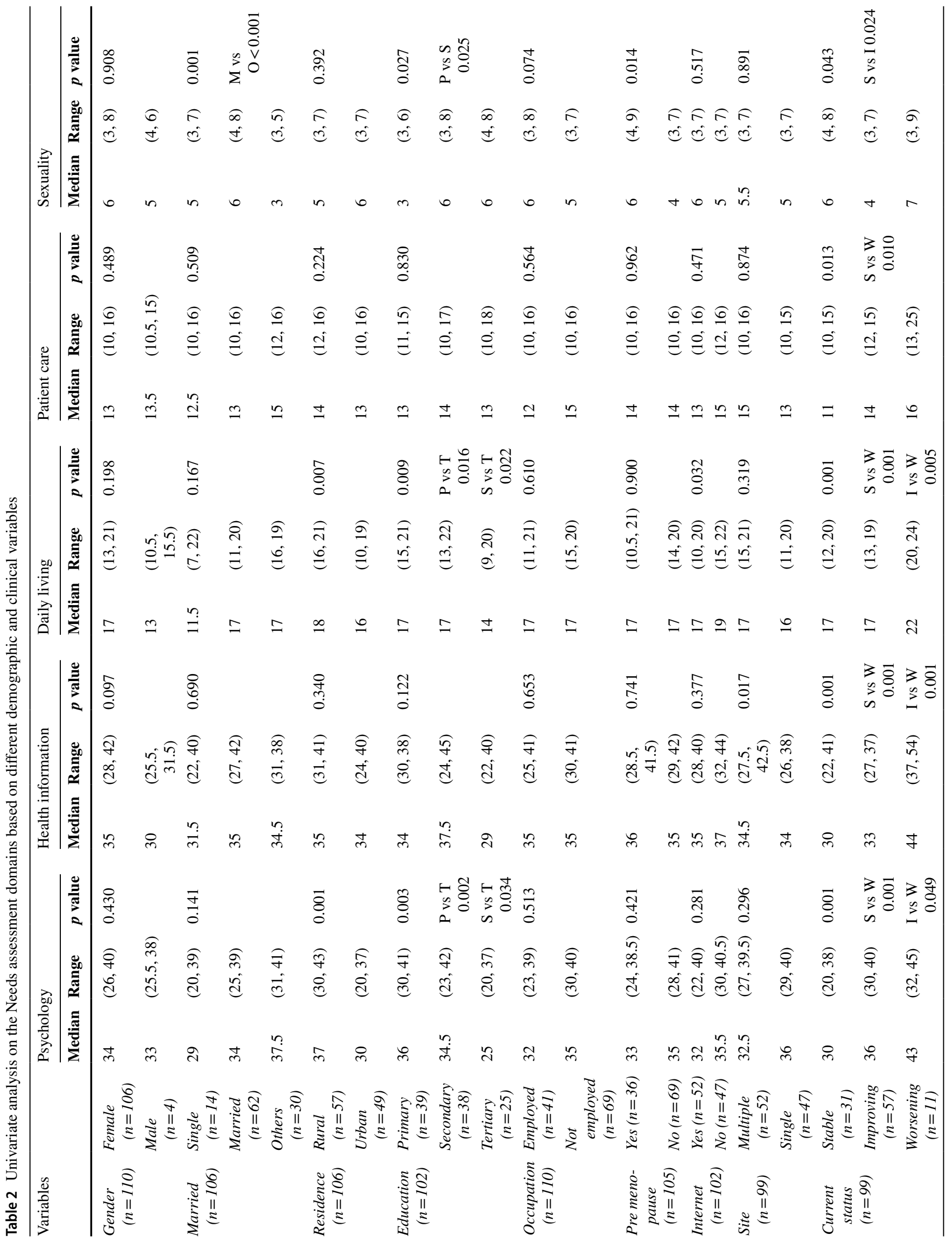




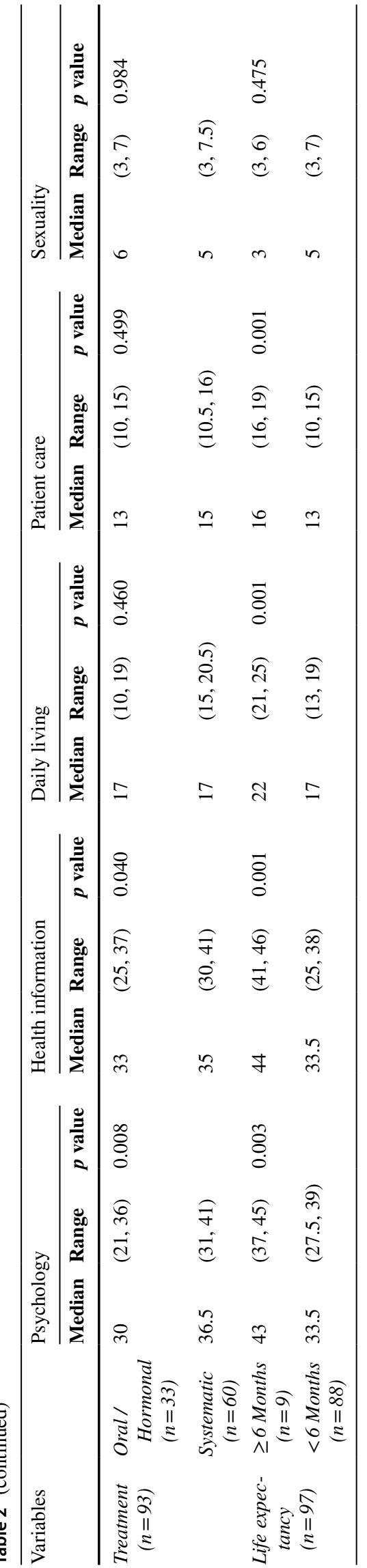

\section{Needs and QoL assessment}

Individual domains based on the needs and FACT-B assessment were negatively correlated. As shown in Table 5, FACT-G, FACT-B Total, and FACT-B TOI were negatively correlated with psychological needs, health information needs, daily living needs, and patient care needs. As the FACT-B scores increased the needs on the particular domain decreased $(p<0.001)$. The overall correlations are presented in Supplementary 1.

\section{Knowledge assessment}

Based on the knowledge assessment, $42 \%$ were knowledgeable about the clinical features of breast cancer. Furthermore, $36 \%$ knew the breast cancer pathology, $61 \%$ claimed to know what treatment they were receiving, and $24 \%$ knew the type of breast cancer they were diagnosed with. Awareness of different terms, $54 \%$ were familiar with the term metastatic breast cancer, $10 \%$ were familiar with triple-negative breast cancer, and $13 \%$ were familiar with HER2 breast cancer. Only $24 \%$ reported having received some written information about their cancer and $84 \%$ desired to have a written summary about their disease status. The overall knowledge assessment summary is presented in Supplementary 2.

\section{Assessment of website data}

The website received 46,571 hits and 5,099 visits from August 2018 to Dec 2018. It received 223,266 hits and 7,561 visits from January 2019 to December 2019 and 40,542 hits and 5,099 visits from January 2020 to September 2020. Overall in 2 years, the website has received 7,864 unique visitors defined as the number of unduplicated visitors to the website, 13,944 visits defined as the session that visitors spent on the site, and 379,861 hits defined as the number of interactions with the website that results in data being sent to analytics.

\section{Discussion}

Women with $\mathrm{MBC}$ are a special group of women with $\mathrm{BC}$ with unique needs which evolve over the period [12]. Improved diagnosis and treatment have resulted in a growing number of women living with MBC [13]. While undergoing different treatment modalities over time, these patients not only go through clinical phases of treatment but also through social and psychological phases of dealing with what is an ultimately incurable disease. While research has largely focused on efforts to improve survival, less attention has been paid to the needs and QoL of patients living with MBC [14]. The sub-Saharan African MBC population seems 


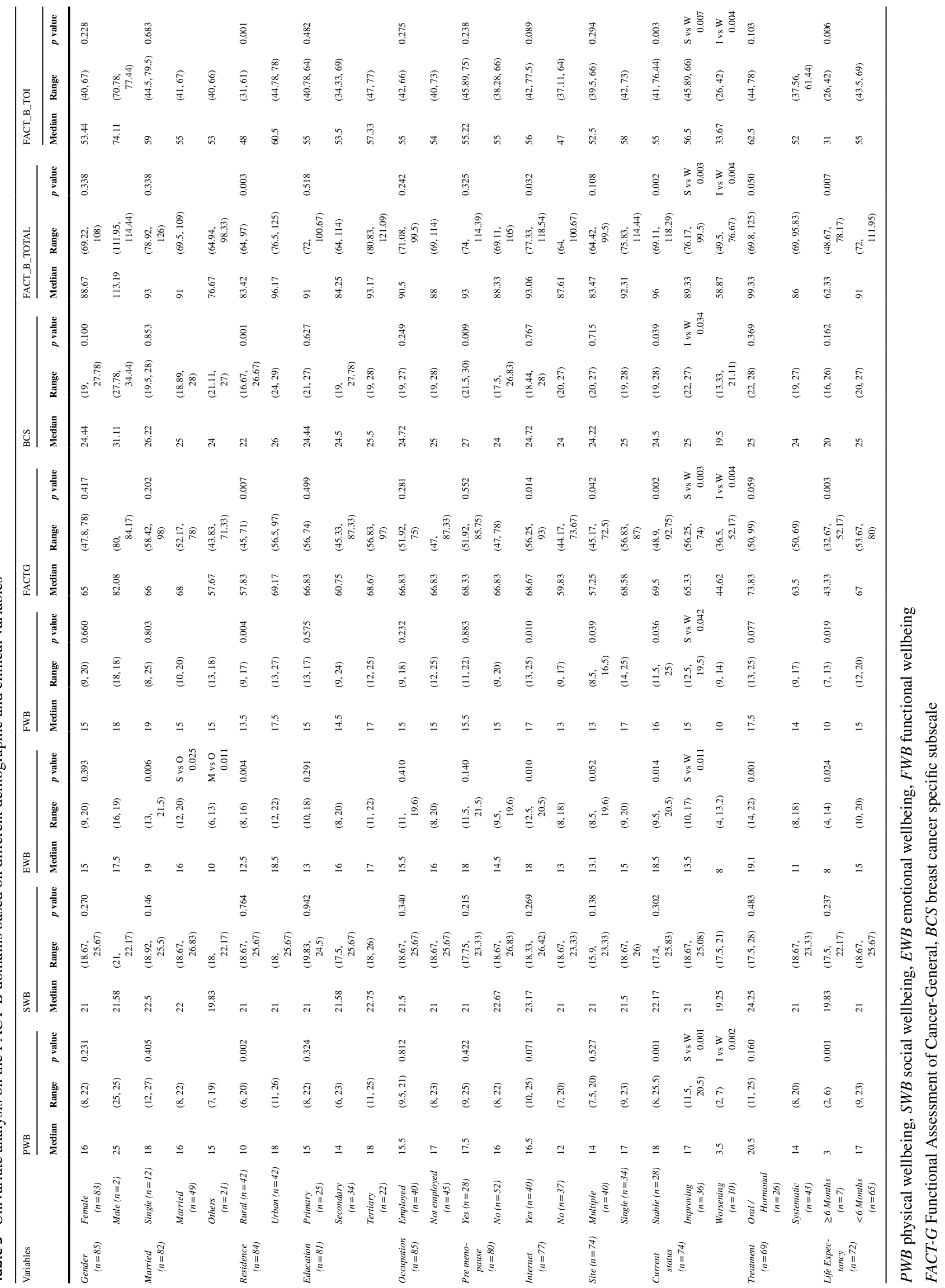


Table 4 Correlations between the Needs and FACT-B assessment

\begin{tabular}{|c|c|c|c|c|c|c|c|c|c|}
\hline & & $\begin{array}{c}\text { FACT } \\
\text { G }\end{array}$ & $\begin{array}{l}\text { FACT B } \\
\text { TOTAL }\end{array}$ & $\begin{array}{l}\text { FACT B } \\
\text { TOI }\end{array}$ & Psychology & $\begin{array}{c}\text { Health } \\
\text { Information }\end{array}$ & $\begin{array}{l}\text { Daily } \\
\text { Living }\end{array}$ & $\begin{array}{l}\text { Patient } \\
\text { Care }\end{array}$ & Sexuality \\
\hline FACTG & \begin{tabular}{|c|}
$\rho$ \\
$p$ \\
value \\
\end{tabular} & 1 & $\begin{array}{l}.982^{* *} \\
<0.001\end{array}$ & $\begin{array}{l}.916^{* *} \\
<0.001\end{array}$ & $\begin{array}{l}-673^{* *} \\
<0.001\end{array}$ & $\begin{array}{c}.339 * * \\
0.001\end{array}$ & $\begin{array}{l}-672^{* *} \\
<0.001\end{array}$ & $\begin{array}{l}-.491 * * \\
<0.001\end{array}$ & $\begin{array}{l}0.129 \\
0.236\end{array}$ \\
\hline FACT B TOTAL & \begin{tabular}{|c|}
$\rho$ \\
$p$ \\
value
\end{tabular} & & 1 & $\begin{array}{l}.955^{* *} \\
<0.001\end{array}$ & $\begin{array}{l}-.713^{* *} \\
<0.001\end{array}$ & $\begin{array}{c}.361^{* *} \\
0.001\end{array}$ & $\begin{array}{l}-666^{* *} \\
<0.001\end{array}$ & $\begin{array}{l}-.528^{* *} \\
<0.001\end{array}$ & $\begin{array}{l}0.091 \\
0.404\end{array}$ \\
\hline FАCT B TOI & $\begin{array}{c}\rho \\
p \\
\text { value }\end{array}$ & & & 1 & $\begin{array}{l}.691 * * \\
<0.001\end{array}$ & $\begin{array}{l}-.395^{* *} \\
<0.001\end{array}$ & $\begin{array}{l}-.728 * * \\
<0.001\end{array}$ & $\begin{array}{l}-.545^{* *} \\
<0.001\end{array}$ & $\begin{array}{l}0.029 \\
0.791\end{array}$ \\
\hline Psychology & \begin{tabular}{|c|}
$\rho$ \\
$p$ \\
value
\end{tabular} & & & & 1 & $\begin{array}{l}.500 * * \\
<0.001\end{array}$ & $\begin{array}{l}.671^{* *} \\
<0.001\end{array}$ & $\begin{array}{l}.625^{* *} \\
<0.001\end{array}$ & $\begin{array}{l}-0.176 \\
0.105\end{array}$ \\
\hline Health Information & $\begin{array}{c}\rho \\
p \\
\text { value }\end{array}$ & & & & & 1 & $\begin{array}{l}.480^{* *} \\
<0.001\end{array}$ & $\begin{array}{l}.673 * * \\
<0.001\end{array}$ & $\begin{array}{l}0.005 \\
0.964\end{array}$ \\
\hline Daily Living & \begin{tabular}{|c|}
$\rho$ \\
$p$ \\
value \\
\end{tabular} & & & & & & 1 & $\begin{array}{l}.483 * * \\
<0.001\end{array}$ & $\begin{array}{l}-0.061 \\
0.579\end{array}$ \\
\hline Patient Care & $\begin{array}{c}\rho \\
p \\
\text { value }\end{array}$ & & & & & & & 1 & $\begin{array}{l}-0.096 \\
0.379\end{array}$ \\
\hline Sexuality & \begin{tabular}{|c|}
$\rho$ \\
$p$ \\
value
\end{tabular} & & & & & & & & 1 \\
\hline
\end{tabular}

** Correlation is significant at the 0.01 level (2-tailed)

*Correlation is significant at the 0.05 level (2-tailed)

$N=86$ for all pairwise correlations to be especially neglected in this regard. Some attempts have been made to highlight inequities in the receipt of care and lack of education in the breast cancer population, but overall there are negligible publications on this subject from SSA [15]. One of the largest international patient-based surveys to study the needs and QoL of patients with MBC did attempt to include countries from low- and middle-income countries (LMICs), but SSA was still excluded from the study population [16]. Even from the standpoint of western research focus, the MBC population despite their unique challenges remains an understudied population, and most of their needs go unreported [16]. Studies from the western literature, however, support the notion that women living with $\mathrm{MBC}$ crave more information, prefer online as well as in-person information, seek selective information, have a high level of psychological distress, seek support, are interested in experiences of others, and rely on a strong family system for coping [17]. Emotional, physical, and psychological needs are known to be the major concern of early breast cancer survivors as well [18], and psychological needs have been shown to take precedence in MBC [19].

Our study, which is, perhaps the first from SSA to report on needs and QoL of patients with MBC, assessed by an instrument that has shown reliability, validity, and sensitivity and psychometric sensitivity in several populations groups [10,20], suggests that three most common needs in women living with $\mathrm{MBC}$ from here are psychological, physical assistance in daily living, and health care system needs. Advanced disease, rural residence, less education, and lack of internet access increases their needs. Quality of life is also better in women living in urban areas, having less burden of disease, being on non-chemotherapy treatment, having a postmenopausal status, and having access to the internet. We demonstrate that higher unmet needs are associated with a decrease in QoL. Most support groups and online resources designed for MBC patients are from the west; although the information available is for all, they certainly lack a local connection [21]. To the best of our knowledge, there is no dedicated web resource dedicated to women with MBC from SSA available, except the one we have launched. Realistic usage of internet-based resources has several determinants that constitute important factors in the success of web-based forums for cancer patients [22]. The internet-based forums are a new and unique way of providing support to women in an evolving health care setting, where support itself by any modality is new. We recognize that at this point, accessing the information from a web-based is a metric of success rather than data collection. Several best-known online international patient support resources are beginning to show their impact in terms of data collection and in supporting 
Table 5 Knowledge assessment responses

\begin{tabular}{|c|c|c|c|}
\hline & & Frequency & Percentage \\
\hline \multirow{3}{*}{$\begin{array}{l}\text { Knowledgeable about the clinical features of breast cancer (such as type } \\
\text { of breast cancer, size, stage, lymph nodes) }\end{array}$} & Agree & 44 & $42.3 \%$ \\
\hline & Disagree & 41 & $39.4 \%$ \\
\hline & Neutral & 19 & $18.3 \%$ \\
\hline \multirow[t]{3}{*}{ Knowledgeable about breast cancer pathology } & Agree & 38 & $36.5 \%$ \\
\hline & Disagree & 44 & $42.3 \%$ \\
\hline & Neutral & 22 & $21.2 \%$ \\
\hline \multirow[t]{3}{*}{ Knowledgeable about breast cancer treatment } & Agree & 66 & $61.1 \%$ \\
\hline & Disagree & 23 & $21.3 \%$ \\
\hline & Neutral & 19 & $17.6 \%$ \\
\hline \multirow[t]{3}{*}{ Do you know what type of breast cancer you were diagnosed with? } & Yes & 25 & $23.6 \%$ \\
\hline & No & 42 & $39.6 \%$ \\
\hline & A little bit & 39 & $36.8 \%$ \\
\hline \multirow[t]{2}{*}{ Aware of the term: metastatic breast cancer } & Yes & 56 & $53.8 \%$ \\
\hline & No & 48 & $46.2 \%$ \\
\hline \multirow[t]{2}{*}{ Aware of the term: triple negative breast cancer } & Yes & 10 & $9.7 \%$ \\
\hline & No & 93 & $90.3 \%$ \\
\hline \multirow[t]{2}{*}{ Aware of the term: HER 2 neu positive breast cancer } & Yes & 13 & $12.6 \%$ \\
\hline & No & 90 & $87.4 \%$ \\
\hline \multirow[t]{2}{*}{ Aware of the term: hormone positive breast cancer } & Yes & 14 & $13.6 \%$ \\
\hline & No & 89 & $86.4 \%$ \\
\hline \multirow[t]{4}{*}{ What was the stage of your breast cancer? } & I & 5 & $4.9 \%$ \\
\hline & II & 20 & $19.4 \%$ \\
\hline & III & 30 & $29.1 \%$ \\
\hline & IV & 48 & $46.6 \%$ \\
\hline \multirow[t]{2}{*}{ Did you have any positive lymph nodes? } & Yes & 39 & $54.2 \%$ \\
\hline & No & 33 & $45.8 \%$ \\
\hline \multirow{2}{*}{$\begin{array}{l}\text { Have you ever received a written summary of your breast cancer diagno- } \\
\text { sis, clinical features, pathology, treatment? }\end{array}$} & Yes & 26 & $23.9 \%$ \\
\hline & No & 83 & $76.1 \%$ \\
\hline \multirow{4}{*}{$\begin{array}{l}\text { In general, how would you feel about receiving this type of personalized } \\
\text { breast cancer summary? }\end{array}$} & I would like it & 90 & $84.1 \%$ \\
\hline & I don't need to know & 3 & $2.8 \%$ \\
\hline & I know, but I like more information & 11 & $10.3 \%$ \\
\hline & My doctor has given me all the information & 3 & $2.8 \%$ \\
\hline
\end{tabular}

patient-centered cancer care delivery [23]. In this context, utilization of our website for data collection would be premature; however, visits should be a metric of success. We recognized an ardent longing for more knowledge and information around breast cancer in our women, during our several breast cancer awareness and diagnostic camps conducted and reported previously [11, 24]. Our findings are consistent with several studies that indicate rural residence is negatively associated with QoL, needs, and disease outcomes [25-27]. Our findings from Kenyan women are also consistent with what has been reported from the QoL indicators from other LMICs, which indicate that age, educational level, and status of disease affect QoL [28, 29]. We indicate that internet access is associated with a better QoL; this is an encouraging sign, as Kenya becomes increasingly digitalized [30] our initiative of a web-based forum would perhaps have better uptake. Our website data utilization is an encouraging sign of greater acceptability of internet-based resources for Kenyan women. Approximately 14,000 visits to the website in just 2 years from establishment assert the internet friendliness of this country's population and call for further exploitation of this resource. Our physical contact sample was not broad which remains a study limitation; we assume that since we conducted the camps on one given day, attendance to the site for camp only had financial implications for the patients; therefore, physical sampling remained modest. A constant provider engagement on-site may provide a better uptake of assessment instruments. The IT-based solutions are a potentially powerful way of providing care to cancer patients, distinctively helping them in communication, community activities such as support groups, web-based health information, and e-commerce [31,32]. Depending on needs, 
web sophistication, and familiarity with the specifics of their cancer, the internet can help or hinder patients and their caregivers in these areas. The impact of our website in providing realistic psychosocial intervention is yet to be determined, with the future level of engagement that would enable us to report this and suggest ways of further improvement. We also noted a reduction in the number of website visitors in 2020; this could be attributable to the early days in the COVID-19 pandemic, but the overall interest attests to the fact that in this vulnerable population, web-based support platforms can provide the much-needed access to care and accurate information. There were 22.86 million internet users in Kenya in January 2020, with internet penetration in Kenya of $43 \%$ [30]. With the government's current focus on infrastructure and expansion of the internet making inroads into rural Kenya, the increasing popularity of mobile internet, and availability of low-cost smart phones, there are real opportunities for taking advantage of internet access and acceptability of web based forums in educating women and addressing their needs. Consistent with our findings, internet access is known to assist women with BC from the rest of the world in better addressing their psychological and health information needs [33]. Women with MBC in our population indicated a low level of knowledge about their breast cancer diagnosis, having little understanding of the type of their disease, and craved for more, preferably written reports of their disease. Comprehensive information about the type of disease is known to help alleviate stresses and improve QoL [34].

\section{Conclusion}

Creating a collaborative group of caregivers and establishing the $\mathrm{KMBCN}$ has provided the opportunity for us to understand the psychosocial aspect of this disease better. We recognize that in-person meetings and internet-based platforms are potential resources for reaching out to address the needs of women living with $\mathrm{MBC}$ in a low-income country with a constrained health care system. Our study was not designed to evaluate the acceptability and impact of the web-based forums in alleviating the sufferings of this forum; therefore, we cannot concretely conclude the impact of these forums at this time. Nevertheless, we demonstrate that most women with MBC in Kenya have high unmet needs around psychological support, physical and daily living, and on the information. QoL standards are the least for those living in rural areas, having disease worsening, and for those without internet access. Increased unmet needs are associated with a decline in QoL. Women with MBC have very little knowledge about their $\mathrm{BC}$ types and treatment. We suggest that networks like KMBCN can potentially prove helpful in addressing needs and improve the QoL of MBC patients and are an effective way of reaching out to women in rural areas as well. Networks like KMBCN should work towards educating women, providing psychological support, and improving the health care delivery system.

Supplementary Information The online version contains supplementary material available at https://doi.org/10.1007/s00520-021-06539-5.

Author contribution Asim Jamal: conception and design of the study, grant recipient, and writing the manuscript.

Niha Dhillion: writing the manuscript.

Jasmit Shah: data analysis, statistics, and writing of the manuscript.

Caroline Kathomi: conception of study, data collection, and writing manuscript.

Alfred Kiragu: data collection and writing of the manuscript.

Fredrick Chite: data collection and writing manuscript.

Catherine Nyongesa: data collection and writing manuscript.

Riaz Kasmani: data collection and writing manuscript.

Innocent Abayo: data collection, data compilation, and manuscript writing.

Grace Kirathe: data collection, compilation, consenting process, and manuscript writing.

Shahin Sayed: concept and design, data analysis, and writing of the manuscript, senior author.

Funding This work was funded through an Educational Grant from Union for International Cancer Control (UICC), via Seeding Progress and Resources for the Cancer Community (SPARC) MBC Challenge, awarded to the principal corresponding author.

Data availability Data is available for review.

Code availability NA.

\section{Declarations}

Ethics approval Received as appropriate from participating institutions. Ethical approval was sought from relevant institutions as detailed in the ethical approval section of this manuscript.

Consent to participate All participants consented to the study as per study protocol.

Consent for publication Consented.

Competing interests The authors declare no competing interests.

\section{References}

1. Globocan. https://gco.iarc.fr. 2018

2. Sharma R (2020) Breast cancer burden in Africa: evidence from GLOBOCAN 2018. J Public Health (Oxf)

3. Jedy-Agba E, McCormack V, Adebamowo C, Dos-Santos-Silva I (2016) Stage at diagnosis of breast cancer in sub-Saharan Africa: a systematic review and meta-analysis. Lancet Glob Health 4(12):e923-e935

4. O'Shaughnessy J (2005) Extending survival with chemotherapy in metastatic breast cancer. Oncologist 10(Suppl 3):20-29

5. Harding V, Afshar M, Krell J, Ramaswami R, Twelves CJ, Stebbing J (2013) 'Being there' for women with metastatic 
breast cancer: a pan-European patient survey. Br J Cancer 109(6):1543-1548

6. Gustafson DH, Hawkins R, McTavish F, Pingree S, Chen WC, Volrathongchai K et al (2008) Internet-based interactive support for cancer patients: are integrated systems better? J Commun $58(2): 238-257$

7. https://ca.go.ke/.

8. https://www.uicc.org/sites/main/files/atoms/files/TheAgaKhan University_2017SPARC_ProjectAbstract.pdf.

9. Boyes A, Girgis A, Lecathelinais C (2009) Brief assessment of adult cancer patients' perceived needs: development and validation of the 34-item Supportive Care Needs Survey (SCNSSF34). J Eval Clin Pract 15(4):602-606

10. Brady MJ, Cella DF, Mo F, Bonomi AE, Tulsky DS, Lloyd SR et al (1997) Reliability and validity of the functional assessment of cancer therapy-Breast quality-of-life instrument. J Clin Oncol 15(3):974-986

11. Sayed S, Ngugi AK, Mahoney MR, Kurji J, Talib ZM, Macfarlane SB et al (2019) Breast cancer knowledge, perceptions and practices in a rural Community in Coastal Kenya. BMC Public Health 19(1): 180

12. Cardoso F, Spence D, Mertz S, Corneliussen-James D, Sabelko K, Gralow J et al (2018) Global analysis of advanced/metastatic breast cancer: decade report (2005-2015). Breast 39:131-138

13. Mariotto AB, Etzioni R, Hurlbert M, Penberthy L, Mayer M (2017) Estimation of the number of women living with metastatic breast cancer in the United States. Cancer Epidemiol Biomarkers Prev 26(6):809-815

14 Nahleh ZA, Lin NU, Wolff AC, Cardoso F, collaboration B-N (2013) Perceptions and needs of women with metastatic breast cancer: a focus on clinical trials. Breast. 22(3):370-3

15. Foerster M, Anderson BO, McKenzie F, Galukande M, Anele A, Adisa $C$ et al (2019) Inequities in breast cancer treatment in sub-Saharan Africa: findings from a prospective multi-country observational study. Breast Cancer Res 21(1):93

16. Group MBCAW (2009) Bridging gaps, expanding outreach: Metastatic Breast Cancer Advocacy Working Group Consensus Report. January 25, 2008. Breast. 18(5):273-5

17. http://lbbc.org/LBBC-Library. LBBCL

18. Capelan M, Battisti NML, McLoughlin A, Maidens V, Snuggs N, Slyk P et al (2017) The prevalence of unmet needs in 625 women living beyond a diagnosis of early breast cancer. $\mathrm{Br} \mathrm{J}$ Cancer 117(8):1113-1120

19. Fulton C (1999) Patients with metastatic breast cancer: their physical and psychological rehabilitation needs. Int J Rehabil Res 22(4):291-301

20. Mary Y, Jung MQ, Wa SL (2017) Examining the psychometric properties of the Functional Assessment of Cancer TherapyBreast (FACT-B) among Korean American breast cancer survivors. Cancer Epidemiol Biomarkers Prev (26) (2 Supplement)
21. Ruvanee P Vilhauer PhD (2009) Perceived benefits of online support groups for women with metastatic breast cancer WH, 49:5, 381-404. https://doi.org/10.1080/03630240903238719

22. Han JY, Kim J-H, Yoon HJ, Shim M, McTavish FM, Gustafson DH (2012) Social and Psychological determinants of levels of engagement with an online breast cancer support group: posters, lurkers, and nonusers. J Health Commun 17(3):356-371

23. Clauser SB, Wagner EH, Aiello Bowles EJ, Tuzzio L, Greene SM (2011) Improving modern cancer care through information technology. Am J Prev Med 40(5 Suppl 2):S198-207

24. Sayed S, Moloo Z, Ngugi A, Allidina A, Ndumia R, Mutuiri A et al (2016) Breast camps for awareness and early diagnosis of breast cancer in countries with limited resources: a multidisciplinary model from Kenya. Oncologist 21(9):1138-1148

25. Reid-Arndt SA, Cox CR (2010) Does rurality affect quality of life following treatment for breast cancer? J Rural Health 26(4):402-405

26. Santoyo-Olsson J, Stewart AL, Samayoa C, Palomino H, Urias A, Gonzalez N, et al (2019) Translating a stress management intervention for rural Latina breast cancer survivors: the Nuevo Amanecer-II. PLoS One 14(10):e0224068

27. Rogers-Clark C (2002) Living with breast cancer: the influence of rurality on women's suffering and resilience.a postmodern feminist inquiry. Aust J Adv Nurs 20(2):34-9

28. Sharma N, Purkayastha A (2017) Factors affecting quality of life in breast cancer patients: a descriptive and cross-sectional study with review of literature. J Midlife Health 8(2):75-83

29. Konieczny M, Cipora E, Sygit K, Fal A (2020) Quality of life of women with breast cancer and socio-demographic factors. Asian Pac J Cancer Prev 21(1):185-193

30. https://datareportal.com/reports/digital-2020-kenya\#

31. Pereira JL, Koski S, Hanson J, Bruera ED, Mackey JR (2000) Internet usage among women with breast cancer: an exploratory study. Clin Breast Cancer 1(2):148-53; discussion 54-5

32. Eysenbach G (2003) The impact of the internet on cancer outcomes. CA Cancer J Clin 53(6):356-371

33. Holmes MM (2019) Why people living with and beyond cancer use the internet. Integr Cancer Ther 18:1534735419829830

34. Rutten LJ, Arora NK, Bakos AD, Aziz N, Rowland J (2005) Information needs and sources of information among cancer patients: a systematic review of research (1980-2003). Patient Educ Couns 57(3):250-261

Publisher's note Springer Nature remains neutral with regard to jurisdictional claims in published maps and institutional affiliations. 